\title{
EBSD study of microstructure evolution of ferritic stainless steel during cold rolling and annealing
}

\author{
Chi Zhang,", YijieXu, Liwen Zhang,and YinlinGu \\ School of Materials Science and Engineering, Dalian University of Technology, Dalian 116024, China
}

\begin{abstract}
The microstructure and texture of ferritic stainless steels (FSSs), formed during cold rolling and annealing processes, determine the mechanical properties of final sheet, especially the deep drawing formability. In this work, aNb, Ti stabilized $17 \% \mathrm{Cr}$ FSS was cold rolled with the reductions of $20 \% \sim 70 \%$ and annealed for periods at $700^{\circ} \mathrm{C}$. EBSD technique was used to characterize the microstructure evolution and inhomogeneous deformation strain distribution of the sheet during cold rolling. Partially annealed sheets were also analyzed to observe the nucleation and growth of recrystallized grains. Special attentions were paid on the crystal orientation of the deformed grains and recrystallzed grains. The results infer that in-grain shear band was formed in the cold rolled sample with the reduction higher than $30 \%$, associated with the formation of high deformation strains. And the recrystallized grains prefer to form at some unique grain boundaries and in-grain shear bands. The orientations of recrystallized grains relates to the deformed grains.
\end{abstract}

Key words: stainless steel, rolling, texture

\section{Introduction}

Ferritic stainless steels (FSSs), which have lower cost as compared to austenitic stainless steels due to the absent addition of $\mathrm{Ni}$, can be widely used for elevator panel, kitchen equipments, home appliance, automotive exhaust manifolds, and so on [1]. They possess excellent properties, such as high stress corrosion cracking (SCC) resistance, high thermal conductivity, low thermal expansion, and preserving magnetic. However, the formabilityof FSSs, especially deep drawing formability, is lower than the austenitic stainless steels. Researches confirmed that the formability of FSSs is closed related to the texture. The component of $\gamma$-fibre texture $(<111>/ / N D)$ is supposed to be benefit for the improvement of formability [2, 3, 4, 5]. Therefore, many efforts have been devoted to develop the texture of FSSs through processing [6, 7]. The microstructure and texture undergo intensive changes during cold rolling and annealing processes [8, 9]. Recently, the EBSD technique is increasingly used to clarify the micro-texture and grain boundary character since it's powerful in analyzing crystal orientation. The aim of this paper is to characterize the microstructure and texture evolution during cold rolling and annealing processes using EBSD technique.

\section{Experiments}

Table. 1 shows the chemical compositions of the tested $17 \% \mathrm{Cr}$ FSS, in which $\mathrm{Nb}$ and $\mathrm{Ti}$ were added to stabilize $\mathrm{C}$ and $\mathrm{N}$ atoms. The hot rolled and annealed sheets with thickness of $5 \mathrm{~mm}$ were obtained from Bao steel company. The sheets were then cold rolled with the reduction of $20 \%, 30 \%, 40 \%, 50 \%, 60 \%$ and $70 \%$ by a 6-high pilot cold rolling mill with the work roll diameter of $110 \mathrm{~mm}$ in lab. Lubricant oil was used during cold rolling. The cold rolled sheets were annealed at $700{ }^{\circ} \mathrm{C}$ for a period. Specimens were cut from the sheets for microstructure and texture observations. The recrystallized fractions of partially annealed samples were calculated from the microstructure observations. EBSD technique, which equipped in a field emission SEM, was used for the orientation detection. The data were typically obtained with a step size of $0.15-0.25 \mu \mathrm{m}$ depending on the grain size. Then the data were processed using HKL Channel 5 software.

Table.1 Chemical compositions of tested material

\begin{tabular}{cccccccc}
\hline $\mathrm{C}$ & $\mathrm{Si}$ & $\mathrm{Mn}$ & $\mathrm{P} / \mathrm{S}$ & $\mathrm{Cr}$ & $\mathrm{N}$ & $\mathrm{Ti}$ & $\mathrm{Nb}$ \\
\hline$\leqslant$ & $\leqslant$ & $\leqslant$ & $\leqslant$ & $16.0 \sim$ & $\leqslant$ & $\leqslant$ & $\leqslant$ \\
0.015 & 0.6 & 1.00 & 0.05 & 18.0 & 0.015 & 0.30 & 0.30 \\
\hline
\end{tabular}

\section{Results and Discussions}

\subsection{Microstructure characters during cold rolling}

Fig. 1 shows the orientation maps of cold rolled sheets with different reductions. After cold rolling, the microstructures were composed of elongated ferrite

*Corresponding author: zhangchi@,dlut.edu.cn 
grains. The width of the deformed grains decreases dramatically with the increasing reduction. In-grain shear bands, which have inclination to the rolling direction by $20-35^{\circ}$, were formed at the cold rolling reduction higher than $30 \%$.
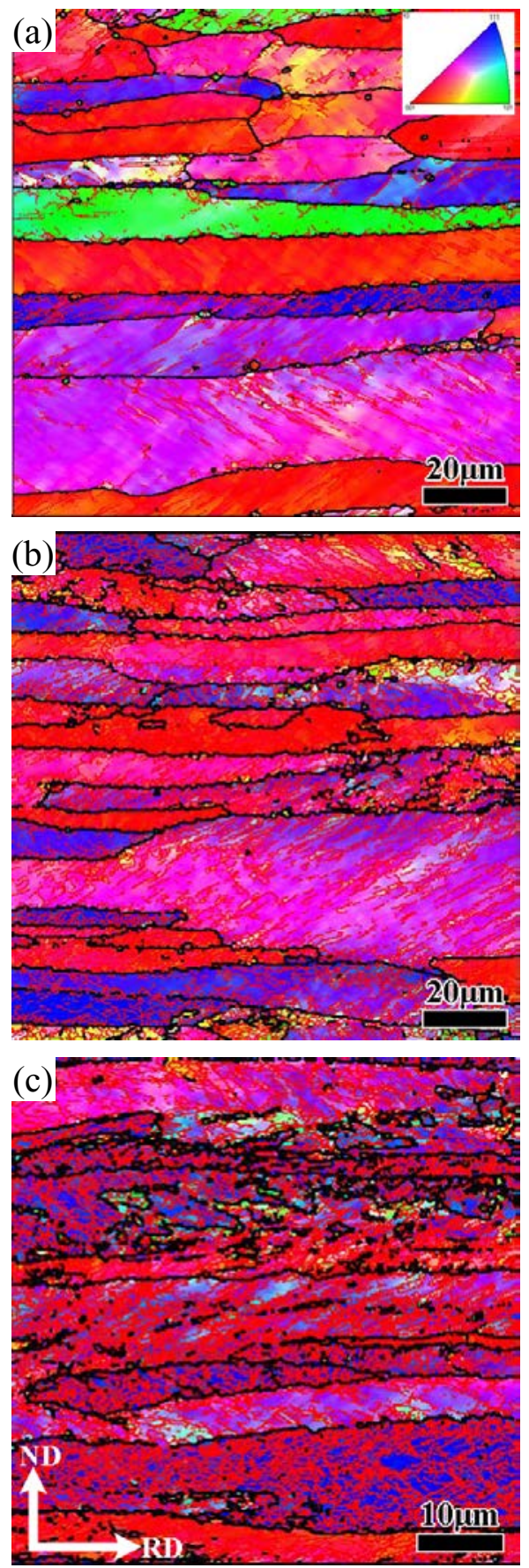

Fig.1Orientation imaging maps of cold rolled sheets with different reductions. a $30 \%$, b $50 \%$, c $70 \%$.

Based on the quantitative data of crystal orientations, the nature of grain boundary and misorientation between adjacent detected points can be calculated using HKL channel 5 software. Fig.2 shows the grain boundary characters of the cold rolled sheet corresponding to Fig.1. The high angle grain boundary (HAGB) is defined by a misorientation between adjacent grains $\theta>15^{\circ}$, and low angle grain boundary (LAGB) is defined by
$\theta<15^{\circ}$.It is found that with the increasing of cold rolling reduction, the numbers of LAGB increase intensively, especially at the grains with in-grain shear bands. This infers that more fragmented grains and subgrain structure were obtained by cold rolling. And these fragmented grains preserve more stored energy for recrystallization in the subsequent annealing process.
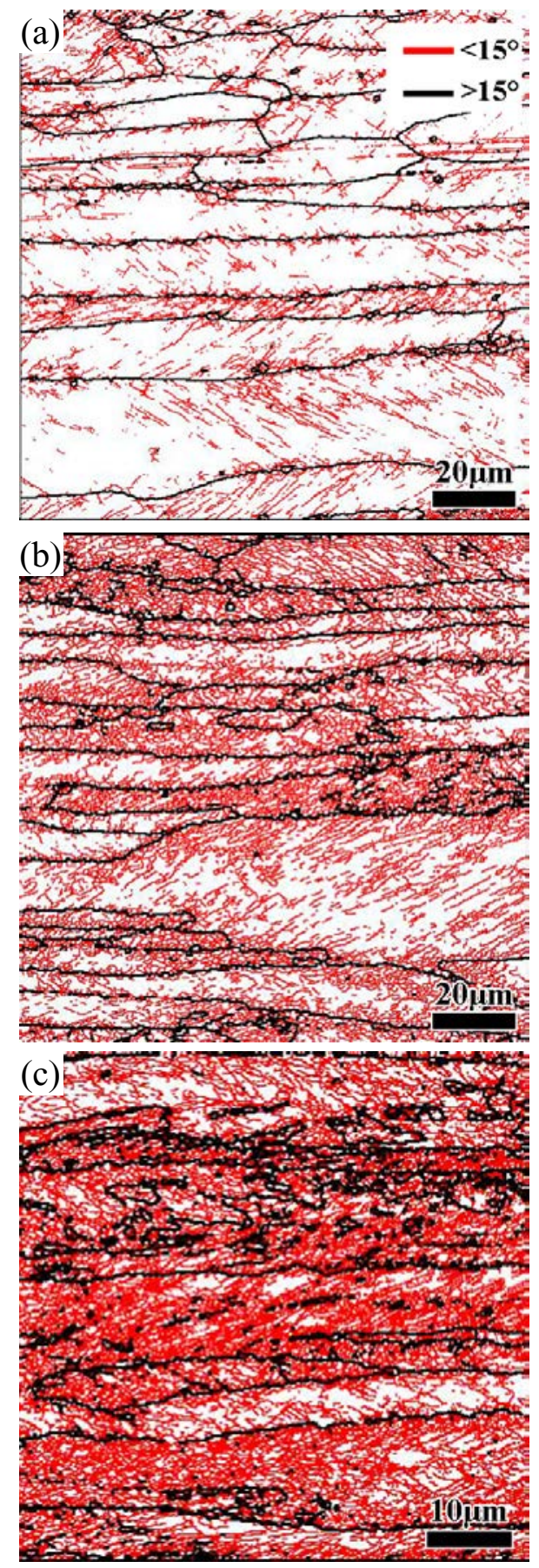

Fig.2Grain boundary maps of cold rolled sheets with different reductions. a $30 \%$, b $50 \%$, c $70 \%$.

Fig. 3 shows the $\varphi_{2}=45^{\circ}$ sections of the ODFs calculated from the EBSD data. Strong rolling texture components near $\{112\}<110>$ were displayed in all sheets. The fraction of $\gamma$-fibre texture increases with the increasing reduction, indicating that compression 
deformation promotes the grains rotating to the $<111>/$ /ND direction. It should be mentioned that the ODFs just indicate the texture of the EBSD detected areas which is supposed to be micro-texture. Nevertheless, the evolution of texture with cold rolling reduction is obvious.

(a)

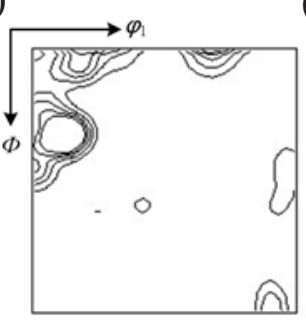

(b)

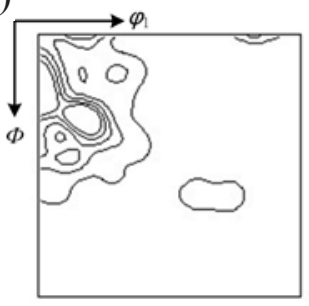

(c)

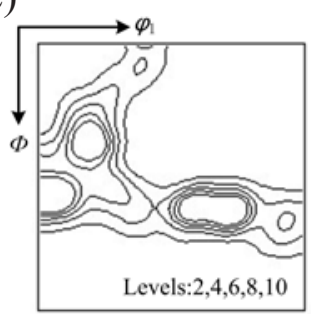

Fig. $3 \varphi_{2}=45^{\circ}$ sections of the ODFs for cold rolled sheets with different reductions.a $30 \%$, b 50\%, c $70 \%$.

\subsection{Microstructure after annealing}

The cold rolled sheets with reductions of $50 \%, 60 \%$ and $70 \%$ were annealed at $700{ }^{\circ} \mathrm{C}$ for different times. The microstructures of the specimens were observed and the recrystallization fraction was calculated as the recrystallized fraction ratio. Then the recrystallization kinetics of the cold rolled tested steel was obtained, as shown in Fig.4.

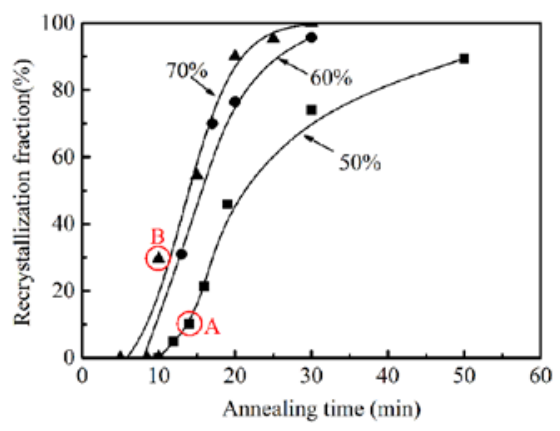

Fig.4The recrystallization kinetics of cold rolled sheets during annealing.

After an incubation period for nucleation of recrystallized grains, the recrystallization fraction increases rapidly with the increasing time. At the later period of annealing process, the increasing rates of recrystallization fraction decreases. The curves indicat that the kinetics follow the Johnson-Mehl-AvramiKormogorov (JMAK)-type kinetics. It founds that the recrystallization kinetics incrases dramatically with the increasing cold rolling reduction. For example, the recrystallization fraction of $50 \%$ cold rolled sheets is about $45 \%$ when annealed for $20 \mathrm{~min}$ while the recrystallization fractions increase to $75 \%$ for the sheet with $60 \%$ reduction and $90 \%$ for the sheet with $70 \%$ reduction. This is because that more energy is stroed in the sheet with the increasing reduction, stimulating the recrystallization kinetics of FSS sheet.

The partially annealed sheets, noted as A and B in Fig.4, were examined using EBSD technique to comprehensively characterize the recrystallization evolution during annealing, as shown in Fig.5. For the sheet with $50 \%$ reduction and annealed for $14 \mathrm{~min}$, only a few recrystallized grains were formed. And most of the recrystallized grains were formed at grain boundaries. Orientation analysis indicates that the recrystallized grain prefer to nucleate at the grain boundary of $\gamma / \alpha$ and $\gamma / \gamma$ boundaries. This result is similar to the observation by Sinclair et al $[10,11]$. While for the sheet with $70 \%$ reduction and annealed for $10 \mathrm{~min}$, more recrystallized grains formed. The newly formed recrystallized grains not only nucleate at grain boundary but also grain interiors with in-grain shear bands as shown in the center area in Fig.5b. This infers that the grains with in-grain shear bands can also be served as nucleation sites for recrystallization.
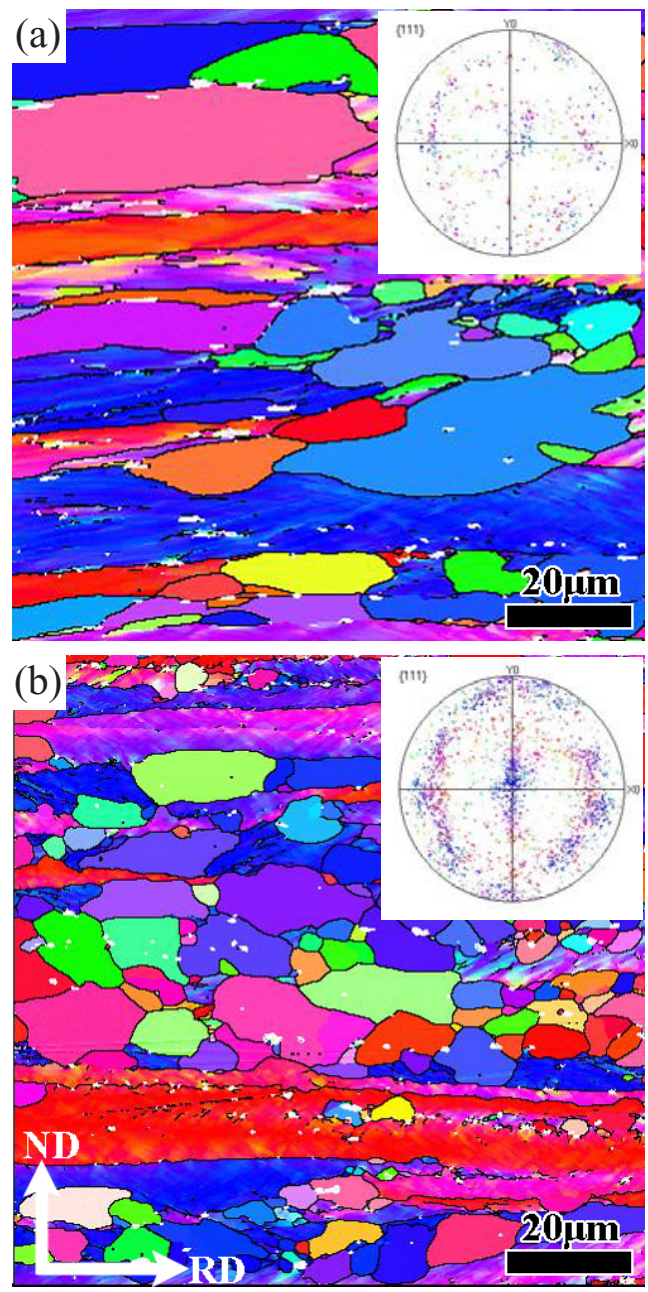

Fig.5Orientation imaging maps ofpartially annealed cold rolled sheets. a sheet with $50 \%$ and annealed for $14 \mathrm{~min}$, b sheet with $70 \%$ reduction and annealed for $10 \mathrm{~min}$. ( $\{111\}$ pole figures indicate the orientations of the recrystallized grains) 
Orientation analysis indicates that the orientations of newly formed recrystallized grains in Fig5a and b have realtions with the deformed grains. The deformed grains with blue colors, which have orientations near to $<111>/$ ND, have prioriety to recrystallization. The newly formed grains inherit the orientations of deformed grainswith $\{111\}<11-2>$ and $\{111\}<1-10>$. This character is same to the IF steel [12]. It is suggested that these grains seem to grow faster than other grains through the mobile of low energy CSL boundaries [13, 14]. The resutls in this work indicate that the orientations of recrystallized grain with $<111>/ / \mathrm{ND}$ at nucleation period already have priorieties. And this is supposed to contribute the formation of $<111>/ / \mathrm{ND}$ texture in the final sheets, which is benefit for the impovemetn of formability of FSSs. Furthermore, the intensity of $<111>/$ ND texture for the recrystallized grains increases with the increasing reduction. This suggests the $<111>/$ ND texture can be intensified by increasing the cold rolling reduction.

\section{Conclusions}

The microstructure and texture evolution during cold rolling and annealing were investigated in this work. The main conclusions are as follows.

1. With the cold rolling reduction higher than $30 \%$, in-grain shear bands were formed in the cold rolled FSS sheets. With the increasing cold rolling reduction, more LAGBs were formed in the deformed grain interiors.

2. Microstructure observations of the annealed sheets indicate that the recrystallization kinetics of FSS sheet during annealing follow JMAK kinetics and increase with the increasing cold rolling reduction.

3 . The recrystallized grains prefer to nucleate at grain boundaries of $\gamma / \alpha$ and $\gamma / \gamma$ boundaries. With increasing reduction, the recrystallized grains also nucleate at grain interior with in-grain shear bands. And the orientation of recrystallized grains has closed related to the deformed grains. $<111>/ / \mathrm{ND}$ texture can be intensified by increasing the cold rolling reduction

This work was supported by a grant from the National Natural Science Foundation of China (Nos. 51604058), the Fundamental Research Funds for the Central Universities of China, the Open Research Fund from the State Key Laboratory of Rolling and Automation, Northeastern University.

\section{References}

1. K.H. Lo, C.H. Shek, J.K.L. Lai. Materials Science and Engineering: R. 65, 39 (2009).

2. I. Tikhovskiy, D. Raabe, F. Roters. ScriptaMaterialia. 54, 1537 (2006).

3. P.D. Wu, S.R. MacEwen, D.J. Lloyd, K.W. Neale. Materials Science and Engineering: A. 364, 182 (2004).
4. F. Gao, Z.-Y. Liu, G.-D. Wang. Journal of Materials Science. 48, 2404 (2013).

5. H. Liu, Z. Liu, G. Wang. ISIJ International. 49, 890 (2009).

6. Y. Yazawa, Y. Ozaki, Y. Kato, O. Furukimi. JASE Review. 24, 483 (2003).

7. C. Zhang, Z.Y. Liu, G.D. Wang. Journal of Materials Processing Technology. 211, 1051 (2011).

8. H.T. Yan, H.Y. Bi, X. Li, Z. Xu. Materials Characterization. 60, 65 (2009).

9. H.T. Yan, H.Y. Bi, X. Li, Z. Xu. Journal of Materials Processing Technology. 209, 2627 (2009).

10. C.W. Sinclair, J.D. Mithieux, J.H. Schmitt, Y. Brechet. Metallurgical and Materials Transactions A. 36A, 3205 (2005).

11. C.W. Sinclair, F. Robaut, L. Maniguet, J.-D. Mithieux, J.-H. Schmitt, Y. Brechet. Advanced Engineering Materials. 5, 570 (2003).

12. S.-H. Hong, D.N. Lee. ISIJ International. 42, 1278 (2002).

13. D. Raabe, K. Lücke. Materials science and Technology. 9, 302 (1993).

14. D. Raabe. Modelling and simulation in materials science and engineering. 15, 39 (2007). 